\title{
Early Aesthetic Dentistry in the Philippines: An Anthropological Perspective
}

\author{
Angelina A. Atienza \\ Department of Basic Sciences, College of Dentistry, University of the Philippines Manila
}

\begin{abstract}
Aesthetic dentistry in the manner of tooth modification or ornamentation existed in the Philippines long before the Spaniards first arrived. Tooth filing, gold pegging and staining were the popular methods used then. For beauty, style and not to have features similar to that of animals, have been cited as reasons for its practice.
\end{abstract}

Key Words: aesthetic dentistry, tooth modification, tooth filing, gold pegging, staining

\section{Introduction}

The practice of dental ornamentation can be regarded as the earliest form of aesthetic dentistry. Tooth encrustation in Mesoamerica dates as far back as 1400-1000 BC. It has been recorded in Central and South America, Africa, India, Australia, and Asia. In Asia it has been known to exist in Japan, China, Taiwan, Vietnam, Indonesia, Malaysia, and the Philippines. Terms such as tooth mutilation, scarification, modification, ornamentation, decoration, and, until recently, tooth transfigurement have been used to describe these practices. ${ }^{1,2}$

Historical, anthropological and archaeological records give plenty of evidence of its custom in the Philippines. Beautification, style, peer pressure and differentiation from white-toothed animals have all been cited as underlying reasons for its practice. ${ }^{3-7}$

In general, there were six methods of tooth modification in the Philippines: "(1) filing the front teeth down slightly so they are even; (2) filing or sawing the front teeth down even with the gums; (3) filing or chipping the front upper teeth to points; (4) filing concave grooves on the outer surface of the upper front teeth; (5) putting gold caps on filed teeth, or gold fillings or brass wire in holes bored in the front teeth; and (6) dyeing the teeth black." ${ }^{8}$ The Bagobos, Visayans, Bukidnons, Hanunoos, Ilongots, Mamanua Negritos, Manobos, Casiguran Dumagats, Negritos of Pampanga, Negritos of Zambales, Remontados of Rizal, Samals, Sambals, Sangils, Subanuns of Sindangan Bay, Sulod Society,

Corresponding author: Angelina A. Atienza, DDM, MOH

Department of Basic Sciences

College of Dentistry

University of the Philippines Manila

Pedro Gil corner Taft Avenue, Ermita, Manila 1000 Philippines

Telephone: +6323026360 or +6323023983

Email: angieaatienza@gmail.com and the Tirurays are noted to have practiced tooth modification. Tooth filing was most likely observed in the past in Mindanao and Sulu, practiced by 4 of the 7 Negrito groups in Luzon, the Ilongots (a non-Negrito group), and some of the Visayan and Palawan groups, but it appears not to have been performed by any of the highland groups in Luzon. $7,8,9$

\section{Historical records}

The earliest written record appears to have been made in 1178 by a Chinese, Chou Ch'u-fei, who wrote of encountering "a fierce tribe with gold pegged teeth", possibly from the mountains of Mindanao or Borneo. ${ }^{10}$

Spanish chroniclers have contributed significantly to the knowledge of the practices of tooth modification by the early Filipinos. In 1521, Antonio Pigafetta wrote of encountering a native chief of Northern Mindanao "who had three spots of gold in every tooth and his teeth appeared as if bound with gold." ${ }^{\prime 9}$ Accounts in the Boxer Codex, ${ }^{6}$ of Fr. Chirino, ${ }^{11}$ and of Fr. Bobadilla ${ }^{12}$ are similar with regard to their descriptions of customs of the Visayans, in which the teeth are filed either to an even and uniform, or to a pointed and saw-like appearance, stained black or red, and decorated with gold. Practiced from early childhood as a mark of beauty and stylishness, it was noted that "there are among them for this need very great artisans." 6

The 1617 Leyte-Samareño (Waray) dictionary of Fray Sanchez provides information on the local terms used at the time. An entry notes that the "smiles of a person with undecorated teeth were "baga napkangnan huligid [like a chaw of coconut meat]", and that the purpose of the filing of teeth was to make them even and symmetrical, or create spaces between the teeth, or to saw them into points. The process of tooth filing was called sangka. Teeth were stained in a number of ways. Regular chewing of anipay root made the teeth black. To give "the appearance of polished ebony" as well as to preserve the teeth, tapul, a tar-based coating, was applied. For a deep red color, lakha (red ant eggs) were used. Kaso flowers were used to color the teeth and fingernails and the habitual chewing of betel nut heightened and preserved the effect. Gold work on the teeth was termed pusad and the dental worker was a manunusad. Fray Sánchez even gave an example of how the terms were used, "Pilay sohol ko nga papamusad ako dimo [How much will you charge me for gold teeth]?" A gold covering on the tooth, whether it was plating (held by gold pegs) or a crown (extending 
beyond the gum and also held by pegs) is called halop. It was the practice to first flatten the surface of the tooth. Holes were then drilled with the use of an awl called ulok and the gold pegs, bansil, were inserted. Variations in gold decoration could come in the form of simple pegs that "looked like gold dots on ivory dice when filed flush with the surface of the tooth. (Si Awi, king of Butuan, had three in each tooth.) But if the pegs were tack-shaped, their flat heads overlapped like golden fish scales; or if round-headed, they could be worked into intricate filigree like designs similar to beadwork." The gold work was made more attractive if set on a tooth that was stained vermillion red or jet black. ${ }^{13}$

Fray San Buenaventura, in the Vocabulario de Lengua Tagala, recorded the existence of metallurgy or metal working even before the Spaniards arrived and the production of dental inlays with the use of gold. ${ }^{14}$

In Labor Evangélica, Fray Colin writes that the Filipinos' "greatest anxiety and care was the mouth, and from infancy they polished and filed the teeth so that they might be even and pretty. They covered them with a coating of black ink or varnish which aided in preserving them. Among the influential people, especially the women, it was the custom to set some of the teeth most skillfully with gold which could not fall out, and gave a beautiful appearance." 15

Similarly, the $17^{\text {th }}$ century voyager Joseph de Laporte wrote of seeing a nation of Indios who file and stain their teeth as "their great ambition is to have neat and even teeth. They have them filed carefully and then covered with a black tincture for preserving them; women of the highest standing decorate them with thin strips of gold."16

Interestingly, as recalled by his sister Espiridiona, even Andres Bonifacio filed his teeth with a piece of broken earthenware to even them out. ${ }^{17}$

\section{Archaeological evidence}

Archaeological artifacts are physical proof of the practices of the early Filipinos. The earliest evidence of staining is perhaps those found in the Duyong Cave excavation (part of the Tabon Caves) where adult teeth were found to be stained. ${ }^{9}$

An excavation headed by Dr. Carl E. Guthe between 1922 and 1925 in burial caves off the west coast of Samar unearthed hundreds of human teeth showing some discoloration or staining possibly from betel nut, while others had evidence of being filed into points or flattened on the labial surfaces. Many of the graves were associated with Chinese trade vessels that date back to the Sung Dynasty (960-1279 CE). Part of the collection, housed at the Museum of Archaeology of the University of Michigan, consists of 43 human anterior teeth with gold ornamentation. Gold pegging is the term used to describe the process by which the gold is attached to the teeth. In 1937, Dr. Leslie F.
Rittershofer did a detailed technical examination of the 43 teeth and his findings included the following:

- The teeth had holes bored on the labial surfaces numbering anywhere from one to seven which were sometimes arranged in a triangular pattern.

- $\quad$ The holes varied from 1-2.3 $\mathrm{mm}$ in diameter and were drilled using a cylindrical instrument with a round end or base.

- $\quad$ The gold peggings or plates were attached to the teeth purely by mechanical retention as the diameter of the base was larger than that of the surface. The gold was assumed to have been hammered into place.

- Designs ranged from single to multiple peggings, plating of the entire labial surface, some even having four-leaf patterns, and polished.

- $\quad$ Some of the teeth showed decorative filing that gave them a V-shaped appearance, while some showed staining most likely from betel nut.

- Metal analysis of some of the discs showed it to be an alloy of gold, silver and copper. The color and specific gravity however revealed that they were predominantly gold-based.

- Since no caries were found on any of the teeth thus having no need for any restorative measures, and that no gold was found where it could not be seen, he concluded that they were placed solely for decorative purposes. ${ }^{18}$

The Bolinao skull, a cultural treasure of the National Museum, excavated from a $13^{\text {th }}-15^{\text {th }}$ century burial site in Balingasay, Bolinao, Pangasinan, exhibits dental ornamentation on the six upper and lower anterior teeth with a "fish scale design or pattern and pegged with gold wire rivets." 19 Other excavations by the National Museum such as in Calatagan, Batangas, ${ }^{20}$ Sta. Ana, Manila, Bulan, Sorsogon, Pila, Laguna, Marinduque, Samar and Butuan have yielded similar finds of filed, chipped, stained and gold decorated teeth (Figures 1-4). The practice of gold pegging was seen more frequently in central and southern Philippines and that "...all pegged teeth from Museum excavations date from the 'Age of Contact and Trade with the East', or after about 1200 CE."'9

\section{Into the $20^{\text {th }}$ Century}

The practice of tooth modification carried on until the $20^{\text {th }}$ century among the different ethnic groups. Reed reported that the sharpening of the anterior teeth was customary among the Negritos of Zambales. It was done voluntarily and at no particular age. Although mainly for adornment, it also "enabled them to eat corn with greater ease." Called talihan, the process required the operator's precision. ${ }^{21}$ Worcester documented the procedure as "a chip of wood is placed back of the tooth to be operated on, the point of a bolo is pressed firmly against the front surface of the tooth and the bolo is struck with a sharp blow with a 
stick or stone, so that a corner of the tooth is chipped off. This operation is repeated on the other side and an artistic point is thus produced." Admirably the teeth are well preserved and the pulp were kept intact. ${ }^{22}$

Fox documented the Pinatubo Negritos and their practice of teeth chipping. Termed as táyad, it was "considered a mark of beauty and maturity and, more than any other single factor, culturally distinguishes an individual living in the Pinatubo area as a Negrito." His account of the process is similar to that of Reed and Worcester. The operation could be performed by either a man or a woman and should the person whose teeth are being chipped show signs or make a remark about pain during the process he would be obligated to pay the chipper a small fine. And should a fragment of his tooth hit a bystander he was likewise to pay the person who was struck. $^{5}$

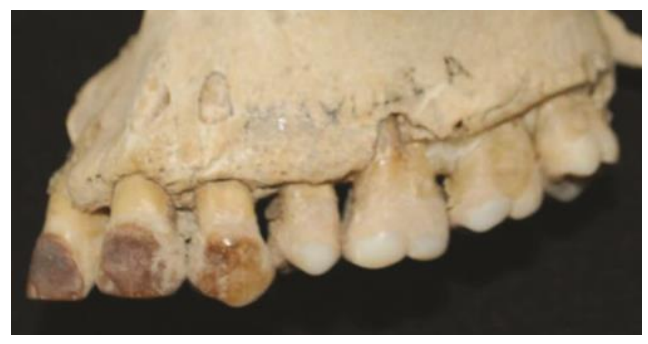

Figure 1. Filed upper left lateral incisor and canine to an even level and its staining along with the upper first premolar. (Courtesy of Mr. Alfredo E. Evangelista)

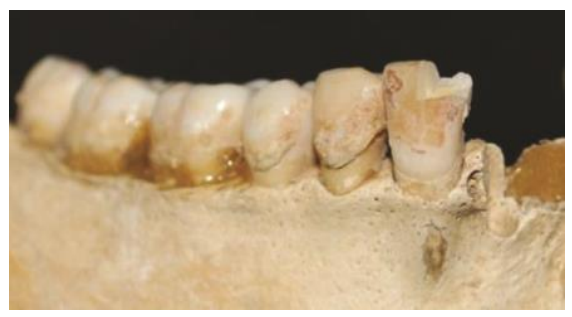

Figure 2. Chipped and stained lower right canine. (Courtesy of Mr. Alfredo E. Evangelista)

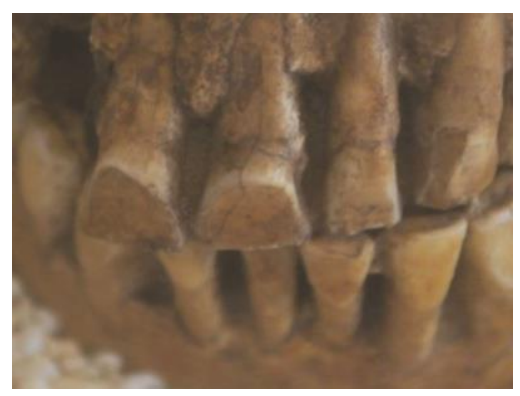

Figure 3. Flattened and stained upper incisors. (From the Puerto Galera Museum)

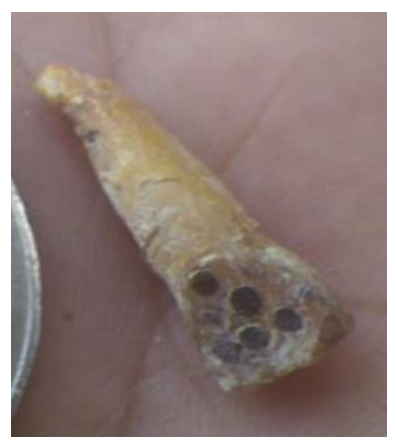

Figure 4. Multiple gold pegging arranged in a triangular pattern of an upper central incisor. Excavated from a burial site in San Remegio, Cebu, it is estimated to be 800 to 1,200 years old. (Courtesy of Mr. Zigfred M. Diaz)

Christie wrote that it was common for the Subanuns to grind their upper front teeth using stones with the effect that the labial surfaces of the incisors appeared concave while the canines were sharpened. The teeth were blackened after. Staining was accomplished by dissolving iron in lime juice or some acidic liquid. This was then rubbed on the surfaces of the teeth. The process was often done when the individual reached maturity. ${ }^{23}$

Cole's report "Wild Tribes of Davao District" documented the Bagobos, Manobos (Kulaman), Tagakaolos (Saka) and the Mandayas (Mansaka) as practicing filing and blackening of teeth. Common to all is that the procedure was practiced by both men and women of the tribe, for the purpose of adornment or beautification and done at about the age of puberty. Cole notes that for the Mandayas it was "so that the young person may be more beautiful and, therefore, able to contract a suitable marriage."

The process of tooth filing and blackening among the Bagobos was described as follows: "the candidate places his head against the operator and grips a stick of wood between his teeth while each tooth is filed so as to leave only the stump, or is cut or broken to a point. When this has been successfully accomplished, what is left of the teeth is blackened."

The staining of the teeth could be done in two ways. Most common was to take a variety of bamboo known as balakayo, whose one end was placed on glowing coals while the other end sat on a piece of metal. This resulted in the "sweating" of the burning bamboo that left deposits on the metal. This deposit was then rubbed at intervals on the teeth for several days until they became shiny black. The second method was to use a powder, tapEl, taken from the lamod tree which Cole believed to be the tamarindus. The powder was wrapped in leaves and chewed. During the treatment period the individual was strictly forbidden to drink water, cook or eat anything sour, or even attend a funeral. If he did, then his teeth would have a poor color or be "sick." Once the 
teeth had been properly beautified the young person was then considered ready to enter society.

For the Mandayas the procedure for filing and blackening the teeth was described as follows: "Filing was formerly done with small stones but imported files are now used for this purpose. The coloring is effected by chewing the roots of the anmon vine and applying to the teeth the 'sweat' caught on a steel blade, held above burning bark of the magawan tree. This practice seems to have no significance other than that of beautifying the person and saving the youth from the ridicule of his fellows. To keep the teeth black, tobacco treated with lemon juice which has stood on rusty iron is chewed frequently."3

In 1922, Cole wrote that the Tinguian men and women blackened their teeth as personal adornment but did not cut or mutilate them. Blackening even took on "a semi-magical procedure. A mixture of tan-bark and iron salts is twice applied to the teeth, and is allowed to remain several hours; but, in order to obtain the desired result, it is necessary to use the mixture after nightfall and to remove it, before the cocks begin to crow, in the morning. If the fowls are heard, while the teeth are being treated, they will remain white; likewise they will refuse to take the color, should their owner approach a corpse or grave." 4

Garvan recounts the practice of tooth mutilation among the Manobos of Mindanao. The process started with the insertion of a piece of wood to separate the teeth. It took about 3 to 6 hours of grinding the teeth and was spread out anywhere from 3 to 10 days. Sandstone was then used to grind both the upper and lower teeth to the level of the gums. When finished "the teeth of the upper jaw appear convex and those of the lower, concave." Both sexes at puberty had their teeth ground. So as not to look like having a dog's mouth are words of encouragement that were often said for the patient to endure the painful process. The maumau plant, which has both narcotic and blackening properties, was chewed and rubbed on the grounded tooth stubs. The practice of betel nut chewing was another way by which the teeth were stained. ${ }^{24}$

Galang noted that dyeing the teeth black was practiced from north to south in the Philippines. The Kalingas stained their teeth to beautify and preserve them and this was done between the ages of 14 to 21 for the men, and at puberty for the women. The local term among the Mañgali-Lubo group is tubug, and beasig for the Lubuagan group. The staining process was described as follows: "The material used is the black resinous substance from dried guava bark, burnt and rubbed against the landuc or babalasigan, an iron implement where the substance is accumulated. Before the subject retires, the black resinous substance is heated and rubbed with the fingers on the teeth until they are entirely black." To maintain the color, the procedure was usually done once a week or when it faded. In Sulu, the mineral antimony was used to stain the teeth black. ${ }^{7}$
In 1977, Headland noted that the practice was still active among the following groups: "in Luzon: Zambales Aeta, Casiguran Dumagat (Agta), Ilongot, and Palanan Dumagat (Agta); in Mindanao: Sangil, Sangir, Ilianen Manobo, Maranao, Tigwa Manobo, Cotabato Manobo, Tagakaulu Kalagan, Mamanua, Ata Manobo, and T'boli; in Palawan: Kalamian Tagbanwa, Molbog; in the Sulu area: Central Sinama (Samal), Yakan, Tausug and Southern Samal." 8

Winters noted that in Bukidnon "adults cut the incisors horizontally across almost midway in their length and then bore a hole through and inlay them with brass wire. They also blacken and stain the teeth." The Negritos "chip their teeth to a point." The Tagbanwas of Central Palawan, men and women alike, "grind their upper teeth with a sandstone and dye them black with lime apag which takes about an hour." For the Ilongots of Nueva Vizcaya, "both males and females file their teeth in a cylindrical shape, so as to separate one well from the other. They are then blackened by the soot and oil from a heated iron. The operation is begun at the age of fourteen." The Pinatubo Aetas of Zambales "clean their teeth with fine sand quartz, do not chew betel, and prize pointed white teeth." The Tasadays ground their front teeth and blackened them as "only animals have white teeth." For the staining practice, after filing, "the enamel of the front surface of the tooth may be removed, more likely to facilitate the blackening of the teeth. For this, a kind of varnish is used. Coconut shell is burnt, and smoke or soot mixed with oil or other ingredients is applied." 9

\section{Conclusion}

Over 900 years after it was described by Chou Ch'u-fei, does the practice of tooth transfiguration still exist?

Twenty-first century aesthetic dentistry now offers tooth bleaching with the goal of attaining the whitest of teeth. Although this is a shift from the previous practice of tooth staining, it still results in the alteration of the tooth's natural color. Meanwhile, whereas filing or chipping the teeth to modify its shape and create spaces between them was the practice then, modern dentistry is more commonly employed to reshape teeth to close gaps and make them more even (Figure 5). Nor is tooth encrustation a thing of the past. Now termed tooth jewelry, tooth bling or twinkles and promoted as "adding sparkle to the smile", it is a trend among the young following celebrities, particularly popular musicians.

Today, tooth ornamentation is less invasive as well as reversible. Instead of drilling the tooth, the ornament is bonded onto the tooth much like an orthodontic bracket. Ornaments can range from yellow or white gold studs to crystals and gems. Dental grills (also called grillz, fronts or golds) are removable dental jewelry that snap over the teeth. These are often made from noble metals (silver, gold or 
platinum) or even base metal alloys with gems set into it to add glitter.

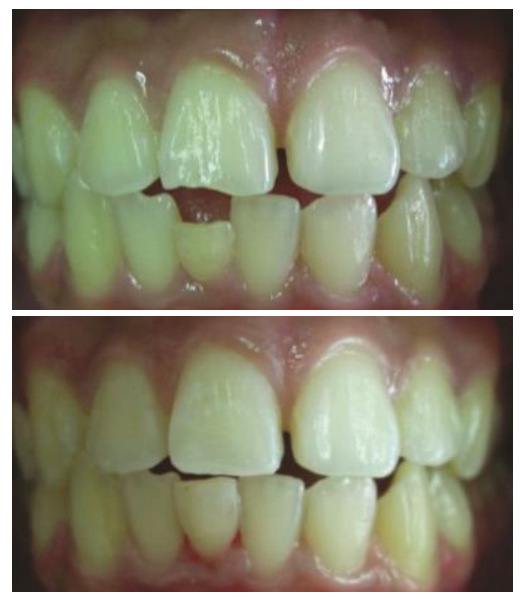

Figure 5. Reshaping of the teeth with composite resin to close gaps make them look more even.

Other variations of present day tooth ornamentation are the addition of metal studs on restorative crowns (Figure 6) and tooth tattooing wherein ceramic crowns are painted with a design of one's choice. A cheaper and very temporary alternative to tattooing is the use of adhesive stickers on the front surfaces of the anterior teeth.

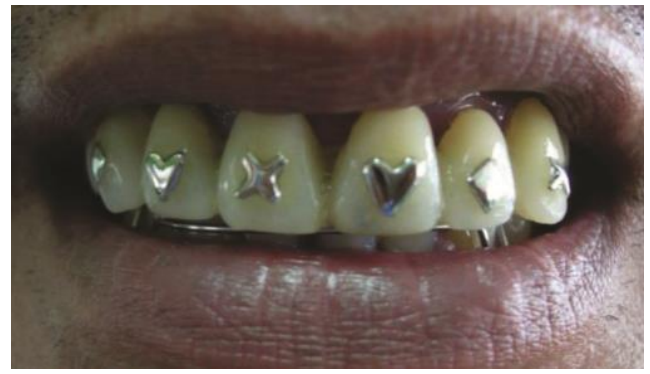

Figure 6. Present day teeth ornamentation with metal studs attached to acrylic crowns.

As was the case hundreds of years ago, to be fashionable and at the forefront of style, the author has observed that the current practices as described above remains a major motivation for the practice of aesthetic dentistry today.

\section{References}

1. Barnes D. Dental Modification: An Anthropological Perspective. University of Tennessee Honors Thesis Projects [Online]. 2010 [cited 2011 Sept]. Available from http://trace.tennessee.edu/utk_chanhonoproj/1345

2. Turner CG. Dental transfigurement and its potential for explaining the evolution of post-archaic Indian Culture in the American Southwest. Dent Anthropol. 2000; 14(1):1-6.
3. Cole FC. The Wild Tribes of Davao District, Mindanao: The R. F. Cummings Philippine Expedition. Field Museum of Natural History, Anthropological Series. 1913;12(2) [Online]. 1913 [cited 2007 June]. Available from http://www.gutenberg.org/dirs/1/8/2/7/18273/18273.txt

4. Cole FC. The Tinguian: Social, Religious, and Economic Life of a Philippine Tribe. Field Museum of Natural History, Anthropological Series. 1922;14(2) [Online]. 2004 [cited 2007 June]. Available from http://www.gutenberg.org/dirs/1/2/8/4/12849/12849.txt

5. Fox RB. The Pinatubo Negritos: their useful plants and material culture. Philipp J Sci. 1952; 81(3-4):173-414.

6. Quirino C, Garcia M. The Manners, Customs and Beliefs of the Philippine Inhabitants of Long Ago; Being Chapters of "A Late $16^{\text {th }}$ Century Manila Manuscript," Transcribed, Translated and Annotated. Philipp J Sci. 1958; 87(4):325-453.

7. Galang RE. Filing and Blackening of Teeth among some Philippine Ethnic Groups. Philipp J Sci. 1941; 75(4):424-433.

8. Headland T. Teeth mutilation among the Casiguran Dumagats. Philipp Q Cult Soc. 1977; 5:54-64.

9. Winters N. The Meaning of a Smile: A crown-to-root analysis of teeth as keys to past population. Filipino Heritage: The Making of a Nation. $1977 ; 2: 449-54$.

10. Scott WH. Pre-Hispanic Source Materials: For the Study of Philippine History (Rev Ed). New Day Publishers; 1984. pp. 26-27, 67, 137.

11. Blair EH, Robertson JA. The Philippine Islands, 1493-1898, Vol 12. Explorations by Early Navigators, Descriptions of the Islands and Their Peoples, Their History and Records of the Catholic Missions, as Related in Contemporaneous Books and Manuscripts, Showing the Political, Economic, Commercial and Religious Conditions of Those Islands from Their Earliest Relations with European Nations to the Close of the Nineteenth Century [Online]. 2005 [cited 2011 Sept]. Available from http://www.gutenberg.org/files/15022

12. Blair EH, Robertson JA. The Philippine Islands, 1493-1898, Vol 29 [Online]. 2012 [cited 2012 April]. Available from http://www.gutenberg.org/ebooks/38748

13. Scott WH. Barangay: Sixteenth-Century Philippine Culture and Society. Ateneo de Manila University Press; 2004. p. 18.

14. Scott WH. Looking for the Pre-hispanic Filipino. New Day Publishers; 1992. p. 81.

15. Blair EH, Robertson JA. The Philippine Islands, 1493-1898, Vol 40 [Online]. 2009 [cited 2011 Sept]. Available from http://www.gutenberg.org/ebooks/30253

16. De Laporte J. The Philippine Islands: Le Voyageur Francois, translated by Pura Santillan Castrence. The National Historical Institute. 1998. p. 19.

17. Ocampo AR. Bonifacio's teeth, Rizal's breath. Phil Daily Inq, 9 Mar 2012 [Online]. 2012 [cited 2012 Mar]. Available from http://opinion.inquirer.net/24571/bonifacio\%E2\%80\%99s-teethrizal $\%$ E2\%80\%99s-breath

18. Rittershofer LF. Gold decorated teeth from the Philippine Islands. J Dent Res. 1937; 16(1):123-33.

19. Legaspi A. Bolinao: A $14^{\text {th }}-15^{\text {th }}$ Century Burial Site. Manila: The National Museum. 1974

20. Fox R. The Calatagan Excavations: Two $15^{\text {th }}$ century burial sites in Batangas, Philippines. Phil Studies: A Quarterly. 1959; 7(3):321-390.

21. Reed W. The Negritos of Zambales. Manila Bureau of Public Printing. 1904. [Online]. 2007 [cited 2009 Aug]. Available from http://www.bohol.ph/books.php\#history

22. Worcester D. The non-Christian Tribes of Northern Luzon. Philipp J Sci. 1906;1(8) [Online]. 2010 [cited 2011 Oct]. Available from http://www.archive.org/details/cu31924023497344

23. Christie E. The Subanuns of Sindangan Bay. Manila: Bureau of Printing. 1909. pp. 52-53 [Online]. 2005 [cited 2012 Mar]. Available from http://name.umdl.umich.edu/ATF7597.0001.001

24. Garvan, J. The Manobos of Mindanao. Memoirs of the National Academy of Sciences, Vol 23, First Memoir, United States Government Printing Office, Washington. 1931 [Online]. 2006 [cited 2012 Feb] Available from http://www.gutenberg.org/files/18607 